\title{
Managing Employees in Interlibrary Loan, Circulation and Reserves: Supervision in a Production Environment
}

\author{
Karen L. Janke \\ Cherié L. Weible
}

\begin{abstract}
In a production environment, strategies for dealing with personnel problems are critical. Two of the most challenging staff problems that an interlibrary loan manager can confront are: (1) How to keep up with work when employees are absent and (2) Employee productivity problems. Interlibrary loan departments face the unique paradox of a workplace that is constantly changing and becoming more efficient due to the influence of technology on daily processes, yet still relies heavily on the daily labor and productivity of the staff. Additionally, interlibrary loan departments face almost constant time pressures, both from internal and external customers. The challenge is magnified when personnel issues arise, and the time needed to problem solve seems nonexistent. In particular, absenteeism and worker productivity can have disastrous results on interlibrary loan service quality, as well as a negative effect on departmental morale. doi:10.1300/J474v17n04_08 [Article copies available for a fee from The Haworth Document Delivery Service: 1-800-HAWORTH. E-mail address: <docdelivery@haworthpress.com> Website: <http://www. HaworthPress.com> (0) 2007 by The HaworthPress, Inc. All rights reserved.]
\end{abstract}

Karen L. Janke is Assistant Librarian and Access Services Team Leader, University Library, Indiana University-Purdue University Indianapolis, 755 West Michigan Street, Indianapolis, IN 46202 (E-mail: kjanke@iupui.edu). Cherié L. Weible is Acting Head of Interlibrary Loan and Document Delivery and Assistant Professor of Library Administration, 128 Main Library, MC-522, University of Illinois, 1408 West Gregory Drive, Urbana, IL 61801 (E-mail: cweible@uiuc.edu).

Journal of Interlibrary Loan, Document Delivery \& Electronic Reserve Vol. 17(4) 2007

Available online at http://jildd.haworthpress.com (c) 2007 by The Haworth Press, Inc. All rights reserved. doi:10.1300/J474v17n04_08 
KEYWORDS. Absenteeism, supervision, management, morale, production-oriented workplace, interlibrary loan, circulation, electronic reserves

\section{INTRODUCTION AND LITERATURE REVIEW}

There is no shortage of literature on management issues in libraries. The challenge for a new manager of an interlibrary loan department is to find texts that apply general management information to the particular issues faced by interlibrary loan and document delivery units. Rachel Singer Gordon's book, for instance, The Accidental Library Manager, offers valuable insights into managing in a library setting. It addresses different aspects of management including personnel issues, managing diverse groups, communication, leadership, and managing change. Even the most seasoned manager can glean new ideas about management styles and libraries by reading her book. Additional resources for hiring, budgeting, and assessment can be found in Lee Andrew Hilyer's recent book, Interlibrary Loan and Document Delivery: Best Practices for Operating and Managing Interlibrary Loan Services in All Libraries, published simultaneously as the Journal of Interlibrary Loan, Document Delivery \& Electronic Reserve, volume 16, numbers 1/2. Volume 17 numbers 1/2 of Collection Management featured several articles on management in access services, notably those by Lange and Tietjen, Chang, Cameron-Miller, and Brown. Unfortunately although providing guidance in many aspects of management, none of these resources addresses two of the most challenging staff problems that an interlibrary loan manager can confront:

- How to keep up with work when employees are absent

- Employee productivity problems.

\section{GETTING OFF TO A GOOD START}

For librarians working in the areas of interlibrary loan, document delivery, circulation, or electronic reserves, it is almost impossible not to have some level of supervisory responsibilities over other staff members, be they librarians, full- and part-time permanent staff, preprofessional graduate assistants, interns or undergraduate students. Yet, in many library science graduate schools, a class on library management is 
not required, or a library school student may take a class but not find themselves in a supervisory role until years later.

Management is not just about handling problem employees: Even the best employees will need training, mentoring and other supervision or will encounter an unanticipated personal crisis that affects their work. Successful management is often time consuming. The time you spend on management issues will vary from day to week to month, depending on the workload of the department and the specific stresses and strains of staff members. If you take the time to nurture high-performing employees, you can reap the rewards later when there is a more serious problem and/or you need someone to whom you can delegate tasks. Arming yourself with valuable tools and resources before a crisis occurs will help you to make sound decisions and reduce the frustrations and potential for burnout when working with staff in a production environment.

A first step for every manager is to acquaint himself or herself with the human resources manager in the library or in the larger organization to which the library belongs. It is imperative to learn how your employees accrue and spend vacation, sick, and/or personal time, how the Family and Medical Leave Act (FMLA) is implemented at your institution, and, if your library has a union, how the union rules impact your options as a manager. The human resources manager will clarify these policies, help you interpret situations that are unclear, and be your partner if you need to take disciplinary actions toward an employee. Second, you must familiarize yourself with the disciplinary procedures in use in your organization so that you can handle situations efficiently and correctly. If no one in Human Resources or your library's administration approaches you about these issues, do take the initiative and time to approach them.

Your staff cannot and will not meet your expectations if they do not know what they are. New supervisors should take the time to get to know the staff and the workflow, but as soon as practicable, it is important to have a discussion with each employee about their primary job duties and your performance expectations. Do not wait until the formal annual review.

Managers who work in the same office space as their staff should find a quiet, private office in which to talk to employees.

It is typical for some type of an annual review process to already be in place and be required at the library or institutional level. Take reviews seriously and although a poor review session can be an uncomfortable situation, it is an opportunity for performance expectations to be revisited and reiterated, and clear up any misunderstandings. The performance 
review is also either a time to identify good work habits and to reward employees in written form, verbally, or both.

There is a saying that you should catch your employees doing something good, and announce it publicly. This kind of positive reinforcement will go a long way in building a relationship between you and your staff and can be a great way to motivate people. Some institutions have formal "pat on the back" letters that can be written and placed in an employee's permanent file at any time. Other institutions do not have formal programs, but written recognition of good work is generally not discouraged. If it is, an informal note or card can be considered, instead.

Since interlibrary loan operations are often technology intensive, it is important to empower staff by encouraging attendance at training sessions and to build training into your unit's schedule. Whether you have weekly, monthly, or quarterly training sessions, you must make time for training even while keeping up with daily work. If you can either slightly overschedule people on training days, get help from other staff members who have been cross trained, or just accept that backlogs will occasionally exist. When staff members are able to use the technology tools and software provides a boost for dealing with the large volume and variety of requests that interlibrary loan staff work with everyday.

Quick Tips for All Managers

$\checkmark$ Develop a thick skin-you will not be liked by all employees all of the time but you should generally be thought of as fair

$\checkmark$ Management is not personal, it is business, but staff members may perceive it as personal

$\checkmark$ Address problems quickly-the anticipation of a conflict is often worse than the actual conflict itself or what happens if it is not addressed

\section{WHEN THE PROBLEMS AT HOME COME TO WORK: LIFE CRISES AND REFERRAL TO ASSISTANCE PROGRAMS}

After you have acquainted yourself with both your staff and the bureaucracy of your organization, chances are it will not be long before you face a personnel management problem. In production-based environments, such as interlibrary loan departments, teamwork is vital because each step depends on the quality and accuracy of the step before. The interconnectedness of production-oriented processes can make co-workers and managers a tight group, which leads to particular management 
issues. For instance, it is important to recognize the fine line between being empathetic to an employee's personal problems and not becoming overly friendly or personal. If your employees see you as their best friend, it may be more difficult for both of you when the time comes for disciplinary conversations.

Computerized management systems such as ILLiad can also make other employees acutely aware of the request volume and at what stage the requests are at in the workflow. This virtually eliminates an employee's ability to hide their work from their co-workers. It can quickly become an issue for the entire department when one employee develops a major or minor life crisis that affects their work performance or interactions with co-workers.

It would seem that while some individuals need their co-workers to hear the details of their personal tribulations, others prefer that their personal business remain private. When the issue at hand is intensely personal and/or confidential in nature, it is imperative that a manager is sympathetic and fair in the dealings not only with the affected employee, but also fair to other staff members and customers who expect and need the work to be done. Being an effective manager may mean that you are not popular, or are seen as unsympathetic or coldhearted. As a manager, it is important to acknowledge, to an employee, that life can deliver difficult circumstances, but that it cannot be allowed to interfere with the employee's work. This can even be of help to the staff member, who may be tentative about addressing the problem, or may need work to be a break from their problem.

A workplace often resembles a family. Supervisors may feel like parents, at times. Guidelines, direction, support, boundaries, positive attention and discipline are needed in proper doses for a healthy work environment. It is important not to become too paternalistic with an employee when trying to assist and empathize with them during a life crisis. If the employee manipulates the manager into breaking the rules that are enforced for the rest of the department, it will affect the morale of the entire department or even the library. Others may have more patience and consider their loyalty more to their colleague than to the work, but everyone has limits. This is where the Human Resources Manager or Library Director can help you. If you must confront an employee, they can be present both as a witness and to serve as a warning to the employee that you take the situation seriously.

If an employee's personal problem is beyond your abilities as a counselor, ask human resources to refer them to a professional. Some institutions have programs that offer counseling assistance at minimal 
or no charge to help employees. The program at the University of Illinois is called Faculty/Staff Assistance and supervisors may refer employees to the program at any time. Indiana University's program is called the Employee Assistance Program, and in addition to an employer-referral, staff can self-refer to the service. However, these types of programs are not adequate for addressing serious mental health issues, and there may be limits on the number of sessions that a person can use.

Example: A female employee, whom we will call Josie, was experiencing some difficulty working with a male employee whom we will call Alex. About 20 years ago, Josie had been physically abused by her spouse and was hospitalized. One of the effects of this experience was Josie's secretive behavior. She was protective of her personal contact information and suspicious of her environment and co-workers. One morning, Josie abruptly left her work area and the department, upset and frightened that someone was going to hurt her. The departmental supervisor did not know where she had gone or what, if anything, caused her to leave. After consulting the student workers in the department, it became apparent that there had been some interaction between Josie and her male co-worker, Alex. The students had witnessed the interaction, and it was apparent to them that Josie was already upset when she reported to work that day and could not focus on her duties. After Josie had asked Alex the same question for the fourth time about a routine process, he became impatient with her apparent lack of attention and raised his voice in an attempt to get his point across to her. Josie then left abruptly. When she returned to work the next day, Josie met with her direct supervisor and the head of the department to find a solution to her difficulty. She accused Alex of using abusive language with her and admitted that she felt threatened and unsafe in the work environment. She had trouble acknowledging that the student workers who witnessed the interaction were neutral and honest in their assessment of the event and that it was not as hostile as she had portrayed it. After a long discussion to reach a resolution, Josie was also referred to the Faculty/Staff Assistance program to obtain counseling to help her ameliorate the anxieties and fears caused by the abuse she had experienced over 20 years before. After meeting with the Assistance program counselors, the problem was resolved and Josie thanked the head of the department for referring her to the professional program to obtain the counseling services to help her through a short, but difficult, life crisis. 


\section{ABSENTEEISM AND OTHER ATTENDANCE PROBLEMS}

Regular attendance is a condition of employment, but a common situation a manager may face is an employee who is consistently late. The 2005 CCH Unscheduled Absence Survey reports that the average cost of absenteeism (defined as paid, unproductive time) in 2005 was $\$ 660$ per employee at a rate of $2.5 \%$ (p. 147). For 2005, the Bureau of Labor Statistics reports the absence rate of those in education, training or library occupations at $2.3 \%$ for illness or injury. Public Sector occupations in general are higher; with rates of 3.7, 3.6 and 2.8\% for federal, state, and local government, respectively ("Absences from work ..."). The absence rate is the ratio of workers with absences to total full-time wage and salary employment. This means that you should expect to lose between $2.3 \%$ and $3.7 \%$ of scheduled hours to unplanned absences, depending on the sector to which your library belongs. To calculate your own absenteeism rate, see Figure 1.

In the private sector, a direct cost of unscheduled absences is calculated in terms of lost revenue; however, this calculation is either impossible or meaningless for most libraries and interlibrary loan departments. Indirect costs are much more of a burden and include "overtime pay for other employees, cost of temporary workers who replace absent employees, productivity losses, and supervisory time spent rearranging work schedules" (Easton and Goodale, p. 462). Perhaps even more frustrating for a manager is that the results of the CCH 15th Annual Unscheduled Absence Survey indicate that the majority of employees $(65 \%)$ are not absent because of personal illness (35\%). Rather, they are absent for other personal issues: family issues $(21 \%)$, personal needs $(18 \%)$, entitlement mentality (14\%), or stresses (12\%) (p. 145).

FIGURE 1. Calculating Your Absenteeism Rate

\section{Calculating Your Absenteeism Rate}

1. Total the number of hours paid for unscheduled absences.

2. Total the number of paid hours that were actually worked.

3. Divide the total in 1 by the total in 2 .

4. Multiply by 100 to obtain a percentage. 
Attendance problems can be especially onerous for a production-oriented department such as interlibrary loan and document delivery, where work has to be done in a timely manner every day. When one employee is absent, others must cover for the absence, increasing workload and stress. This can breed resentment, especially if the employees who did come to work believe the absence is not legitimate, or if under similar circumstances, they have come to work. Resentment can lead to in-kind retaliation (calling in sick themselves) or negative behaviors directed at the absent staff members when they return to work. By not enforcing the work schedule of each employee and following consistent rules concerning sick and vacation time, a manager may send a message to other employees that they operate using favoritism and apply rules inconsistently among/between employees. If employees perceive another to be "getting away with" frequent and questionable absences, others will feel entitled to the same.

Example: One employee who had a history of alcoholism developed a pattern of absenteeism on Mondays. When the employee was presented with this information and a solution was sought, the employee shared that he was now caring for a family member who was dying of cancer. The employee was a private individual who did not want this information shared throughout the department, but who needed assistance in knowing who to turn to for help. With the assistance of the Human Resources department, the employee was provided with the contact information for hospice and given lenient time off from work as needed. Although the situation resolved when the family member passed away, a new absenteeism problem developed a few months later. The employee began coming to work very late without calling in to report the delayed arrival. After two weeks of this behavior, the supervisor called the employee into a private office and simply stated that the employee was needed to open the office each morning and that in the past, the employee had been highly dependable. The supervisor focused on telling the employee that they were needed to make the operation run smoothly. Fortunately, the situation resolved itself without further disciplinary action.

Attendance problems can be difficult to solve, particularly if they are inherited or long-standing. Some believe that the motivation of a job well done is enough, or that the reward of personal satisfaction and a paycheck is all that is required. The reality is that supervisors are faced with employees for whom the work itself is not a motivating factor and the paycheck is inadequate. Indeed, for those who dislike their jobs, managers need to employ a combination of the proverbial carrot and stick. If there is no carrot or stick, some will be take advantage of you by those for 
whom sick time is just another form of vacation or an entitlement rather than something to be used during emergencies and genuine illness.

What do you do if you find yourself supervising people whose entire existence is one emergency after the other? One strategy is to extend the probationary period for new employees. Six months is usually enough time for this type of behavior to manifest itself. If you are unable to do this based on institutional regulations, it is imperative to monitor attendance closely during the probationary period that you are allowed.

You must document everything and look for patterns: Does the employee call in on Mondays or Fridays to extend the weekend? Does the employee call in sick on a day that they had requested as vacation? Does one employee's absence guarantee that the next day another employee will be absent in retaliation? How long is the employee able to go without an illness or incident?

Another strategy to combat poor attendance is named an attendance management program. Attendance management programs often combine rewards and punishments to encourage good attendance. In their 2002 article in Personnel Review, Dunn and Wilkinson surveyed a variety of industry sectors to evaluate how managers are managing absences. Their article focuses on the pros and cons of different types of attendance management programs based on interviews with frontline managers.

Sanction-based programs typically involve a threshold of absences that an employee is allowed before a negative sanction takes effect. Such programs assist you in identifying patterns of abuse. At the same time, they prevent you from reacting punitively to individuals with legitimate long-term issues (Dunn and Wilkinson, p. 236). This type of program requires absolute consistency, or you will lose credibility. Unions may prevent this type of program. It may cause some employees to take as many sick days as they are allowed before they reach the trigger point. If ten days is the trigger point, does that mean that nine days are acceptable? It also may prevent you from reacting proactively if you must wait until the trigger is reached before you can act (Dunn and Wilkinson, p. 236).

Return-to-work interviews are another tactic. It requires all employees to meet with their supervisors upon return to work from an absence. It allows the supervisor an opportunity not only to inquire about the employee's health or what caused the employee to be absent, but also to communicate the status of the work in the department, what had to be done by others while the employee was away and to reiterate any attendance policies that are in force (Dunn and Wilkinson, p. 237). The downside to these interviews is the time required by management, 
as well as the timing of the interview. If the manager is away when the employee returns, an interview conducted weeks later does not have the same impact as one conducted the day the employee returns.

Financial rewards for good attendance receives little support from the managers interviewed by Dunn and Wilkinson. Many were philosophically opposed to rewarding someone twice for coming to work: once when they were paid and another time when they received an attendance bonus. These bonuses were seen to encourage presenteeism, (the practice of attending work while sick, resulting in lower productivity and risking the health of co-workers) as well as punishing those who were legitimately ill. Most importantly, these bonuses were seen as sending a signal to the worker that the management could not otherwise control absences (Dunn and Wilkinson, p. 238).

Easton and Goodale contend that since absences are inevitable, in addition to attempting to prevent absences, an organization should create an absence recovery procedure (p. 482). Their model calculates the different gains experienced by employing one of three strategies: holdover overtime, regular employees called in at the last minute to substitute and temporary employees. However, the model created by Easton and Goodale is not suitable for most library environments because of our inability to estimate "expected marginal revenue produced by successive units of labor" (p. 461). Libraries experience this difficulty because we have a continuous, long-term relationship with our customers; the delays due to absenteeism are born by the customers both internal and external; and the "monetary opportunity costs for service delays are difficult to measure" (p. 461). Additionally, many libraries, and interlibrary loan operations in particular, are hindered by the varied quantity of requests and the fixed nature of public sector employee work schedules. Overtime may not be an option.

The point to be taken from Easton and Goodale's research may be simply to realize that absences are inevitable, and that perhaps our expectations for worker productivity should be scaled back to account for unscheduled absences. If departments are so tightly scheduled to require perfect attendance to function, there will be staff problems in the interlibrary loan and document delivery departments.

Large public library systems might be able to employ the substitute model for circulation workers, similar to the process school districts use to supply substitute teachers. However, for smaller library systems, the scale is not large enough to warrant a cadre of substitutes. For interlibrary loan or reserve operations, the skill set required is too specialized employ temporary workers. One strategy to ameliorate absences is 
for the library administration to acknowledge the realities of interlibrary loan work. Make it a library priority to staff it fully whenever possible. Cross training within the department is valuable. Implementing a detailed procedures manual that anyone in the library could use to process the routine requests and tasks in the event of an interlibrary loan staff absence is another tactic.

\section{PERFORMANCE ISSUES AND SUCCESSFUL RESOLUTION}

Performance issues are often more difficult to solve and are longer in duration than a personal crisis, although they are sometimes related. Performance problems go beyond a situation where an employee may need additional training in order to perform a task correctly. Some examples of performance issues can be low productivity, time wasted surfing the Internet or e-mailing, excessive time spent talking to coworkers, and even willful disregard for policy or procedure. Do not let situations like these fester. Document the extent to which your employees seem to be wasting time on nonwork activities and make your presence felt in the department. Revisit their job description and your performance expectations.

When you feel you have a good grasp of the extent of the problem, have a meeting with the employee. You cannot wait until the annual review to address a performance problem. Depending on the severity of the situation, shorter performance review discussions can occur monthly, weekly, or even daily. These conversations are not a negotiation; you must limit the discussion to the job-related tasks and set goals or milestones. It may be that the employee was not aware of how much time they were spending on nonwork activities, but do not be surprised if the employee points to co-workers and claims to be no worse than someone else. Refocus the discussion to that specific employee and his/her situation. Acknowledge the choices the employee has, and the consequences. Moreover, if he/she has a point, address the same situation with other employees, as well.

Personality conflicts can also affect the entire office staff and should be treated as a performance issue. Civility and collegiality are part of performance, and if a person cannot get past the personality conflicts, this is "actionable" for performance improvement plans or discipline. Too often, personality conflicts between two or more employees are allowed to take over and ruin the good working potential of the remaining office 
employees. Supervisors should not be afraid to address these conflicts and attempt to neutralize the effect that they have on the working environment.

\section{PERFORMANCE APPRAISALS}

Although your library or parent institution may mandate the form and format of the annual performance appraisal, it may be possible to implement a strategy for performance appraisal and management known as BARS (Behaviorally Anchored Rating System). BARS is based on an initial document known as the Behavioral Performance Standards. This document is based on an employee's job description or identification of the employee's primary job responsibilities. The 6-8 major job duties are written down and high, medium and low levels of performance are identified. The form allows for a variety of performance standards to be used, depending on the nature of the work being evaluated (see Table 1).

The benefit to the Behavioral Performance Standards form is that the employee is aware of the standards upon which they will be judged before any review occurs, and that the standards are fairly applied across the department, rather than subjective. It is just common sense that you tell the employee what you expect from them and then allow them the opportunity to meet the expectations. An employee cannot perform well if they do not know what the performance expectations are.

TABLE 1. Behavioral Performance Standards Examples

\begin{tabular}{ll}
\hline Performance Standard & Examples \\
\hline Quantity & How much or how many must be done \\
Quality & E.g., Process all requests within 24 hours \\
& How well or accurately the job responsibility must be \\
done & E.g., Scans lending articles and checks for quality and \\
& completeness. Fewer than 5 lending re-send \\
& requests per week are desirable. \\
& How fast or by what deadline the job responsibility \\
must be done & E.g., Sends out overdue notices daily. Sends out \\
Timeliness & lending invoices weekly. \\
& Under what cost constraints the job responsibility \\
& must be done \\
Expense & E.g., Hires and schedules student workers within given \\
& budget. \\
& Customer satisfaction; independent initiative required; \\
other relevant, verifiable measures
\end{tabular}


More information on examples of performance standards can be found in Carol F. Goodson's book, The Complete Guide to Performance Standards for Library Personnel.

One benefit of using BARS in interlibrary loan or e-reserves is that there is no shortage of measurable outcomes. The challenge is to decide on the production expectation. One approach could be to decide on a desired turnaround time (e.g., all borrowing requests are placed within 24 hours after the user has placed the request). Another way would be to determine the average number of requests you receive per week, divide by the number of staff involved and create high-medium-low levels of production. One drawback of setting numeric standards is that some employees may purposefully focus on the routine requests in order to meet a quota. Problematic requests could be avoided or unnecessarily cancelled in favor of easy requests in order to meet a certain quota. Managers may need to review the requests employees cancel to determine if this is the case.

\section{CONCLUSION}

Library managers may initially be uncomfortable working with and managing staff if they do not have supervisory experience, or if the only experience they have had has been negative. However, there are a number of tools and resources available to help anyone to become a successful supervisor. Keys to success have been identified in this article, but one of the best pieces of information is to become familiar with the institution where you work and how employee problems and rewards are handled. Your staff is a diverse group of individuals, and recognize that what works well when supervising one employee may not work well with another. Although it may seem as administrators need to look at the big picture, and supervisors deal with daily tasks, supervisors must also understand and communicate to their department members how what they do there contributes to serving patrons and achieving the mission of the organization.

\section{WORKS CITED}

\footnotetext{
"Absences from work of employed full-time wage and salary workers by occupation and industry" Table 47. Employment and Earnings, January 2006. Current Population Survey. Bureau of Labor Statistics, 2006. ftp://ftp.bls.gov/pub/special.requests/lf/ aat47.txt or http://www.bls.gov/cps/cpsaat47.pdf.
} 
"Behavioral Performance Standards" accessible at http://www.hra.iupui.edu/hrforms_ abc.asp "15th Annual Unscheduled Absence Survey." Human Resources Management Ideas \& Trends 616 (2005): 145-56.

Dunn, Caroline and Adrian Wilkinson. "Wish You Were Here: Managing Absence." Personnel Review 31.2 (2002): 228-46.

Easton, Fred and John C. Goodale. "Schedule Recovery: Unplanned Absences in Service Operations." Decision Sciences 36.3 (2005): 459-88.

Goodson, Carol F. The Complete Guide to Performance Standards for Library Personnel. New York: Neal-Schuman Publishers, Inc., 1997.

Gordon, Rachel Singer The Accidental Library Manager. Medford, NJ: Information Today, Inc., 2005.

Hilyer, Lee Andrew, ed. Interlibrary Loan and Document Delivery: Best Practices for Operating and Managing Interlibrary Loan Services in All Libraries Spec. issue of Journal of Interlibrary Loan, Document Delivery \& Electronic Reserve. 16.1/2 (2006: xxv-147). Binghamton, NY: Haworth Press, Inc., 2006.

Sapp, Gregg, ed. Access services in Libraries: New Solutions for Collection Management Spec. issue of Collection Management 17.1/2 (1992: xvi-245). Binghamton, NY: The HaworthPress, Inc., 1992.

\section{doi:10.1300/J474v17n04_08}

